\title{
Some Features of Non-Safety Costs in Maintenance of Work equipment's
}

\author{
Georgeta Buica ${ }^{1}$, Anca Elena Antonov ${ }^{1}$, Constantin Beiu ${ }^{1}$, Dobra Remus ${ }^{2}$, Dragos Pasculescu ${ }^{3}$, M. Ayaz Ahmad ${ }^{4}$ \\ ${ }^{1}$ INCDPM"Aexandru Darabont", Blvd. Ghencea, no. 35 A, Bucharest, 6 County, Romania \\ ${ }^{2}$ Faculty of Exact Sciences and Engineering, University "1 Decembrie 1918" Alba-Iulia, Romania \\ ${ }^{3}$ University of Petrosani, 20 Universitatii str, Petrosani, România \\ ${ }^{4}$ Physics Department, Faculty of Science, P.O. Box 741, University of Tabuk, 71491, Kingdom of Saudi Arabia
}

*Correspondence Author: M. Ayaz Ahmad, mayaz.alig@gmail.com

\begin{abstract}
In the present research article, a modest attempt has been made to find some important features non-safety costs in maintenance of work equipment's. The preventive maintenance is essential in maintaining the safety and reliability of work equipment, which is ensuring the safety and health of workers and also it, give an optimal and safe working environment. Here, we analyze the influence of the failure of the work equipment, as a result of non-preventive maintenance, on the managerial performance of a company. From the analysis of the effects of the costs of work-related events, it was found that the failure and deterioration of work equipment accounted a significant share from the cost of nonsafety. These factors are an argument for the cost - benefit analysis of occupational safety and health. Final, we emphasized some important role of preventive maintenance, namely the necessity to carry out periodic safety tests, starting from the conception of many employers that they have the economic criterion regarding the safety and health of the workers in the work process.
\end{abstract}

Keywords: maintenance, cost, non-safety, management, production mechanism

\section{Introduction}

The maintenance activity is a necessary activity in efficient production, and this must be rigorously planned and applied. From the studies and analysis of statistical data on work accidents and occupational diseases, confusion was found among the small and medium enterprises' employers on the need for preventive maintenance and planned maintenance, opting only for corrective maintenance in case of damage and failure, only for repairs. On the other hand, the preventive maintenance activities, as well as the prevention activity are two activities that do not produce immediate financial benefits; in this sense some of the employers, especially the small and medium enterprises, tend to reduce the budgets allocated to these unproductive activities. The risk assessment should be carried out before any maintenance work begins and work should be planned. It is best practice to keep a maintenance $\log$ which is regularly updated. The workers should be involved in the risk assessment process as those carrying out a maintenance task are often in the best position to identify the most efficient ways of dealing with them. The work area should be made safe (e.g. preventing unauthorized access) and the people performing the maintenance work should be equipped with the proper tools and equipment to do the work safely. The work should be monitored and safe working procedures need to be followed at all times. The process needs to end with checks to ensure that the job has been completed satisfactorily.

\section{Maintenance status at national level}

Maintenance activity is one of the workplace activities that can affect the safety and health of workers, both those using work equipment and those directly involved in it, and failure to carry out preventive maintenance leads to damage and disturbances and sometimes to work accidents and occupational diseases. Analyzing the statistical data on work-related accidents, their causes and their effects and comparing the occupational hazards, it is found that during the lifetime of work equipment the most risks are identified during the maintenance operations.

Fig. 1 presents the weight of the professional risks identified in the preventive maintenance and corrective maintenance activities.

Fig. 2 presents the weight of the professional risks identified in categories of maintenance activities. 


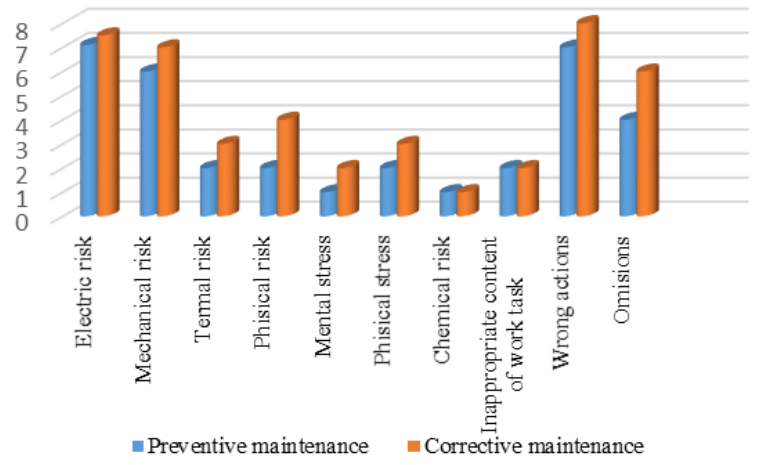

Fig. 1: The weight of risk factors identified in the maintenance activity

Work accidents have a growing tendency not to occur during normal operation, but during repair, maintenance, cleaning, adjustment, etc. as narrated by (A. Antonov et al., 2015) ${ }^{[1]}$ and others $^{[2-3]}$. Analyzing the risk of injury and occupational disease, we find that the electrical risks and the wrong actions have the greatest weight. In this respect it is recommended a rigorous analysis of the causes that generate these factors and especially the analysis of electrical problems from all activities in order to identify the electrical hazards that may occur and cause serious injuries or even the death of worker involved in the work process. (Pasculescu et al., $2012 \&$ others) ${ }^{[4-6]}$. The purpose of analysis of the safety level assessment is to provide the possibility to know the real situation from the point of view of safety and to take the proper prevention methods for the given situation. (Radu et al., 2013 \& others $)^{[7-9]}$.

\section{Cost analysis generated by lack of preventive maintenance}

Knowing, analyzing and controlling all costs at a company level are useful tools for diagnosing the company's situation and its ability to overcome it in the national economy. Maintenance activity is an integral part of production activity, as the place of event progress, effects and application, and is therefore also subject to economic laws. An event caused by failure / damage of work equipment adversely affects the elements of the work system, by the unavailability of damaged work equipment during repair or replacement by discontinuing economic activity, having an effect

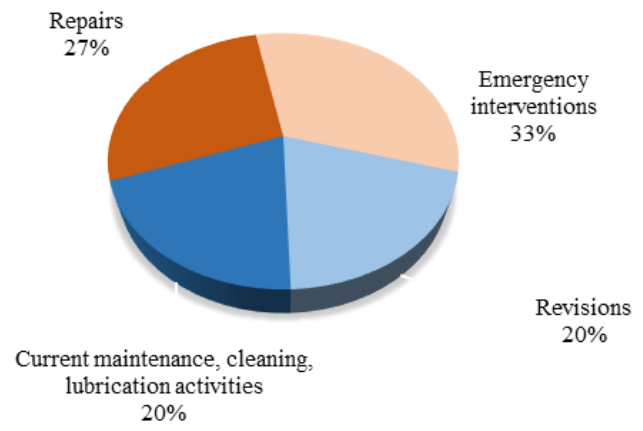

Fig. 2: National work accident statistics, by categories of maintenance activities.

on productivity due to the reduction of the working hours of the personnel, and so on. The main cost of non-maintenance is determined by the value of lost production during the maintenance period due to the unavailability of the work equipment (W-E) / installation. Breaking down the costs by category, the lack of preventive maintenance also entails costs related to overtime payment for the repair / replacement of the W-E, the value of the spare parts, the materials used to repair / replace the W-E, the value of the new work equipment if it can no longer be repaired, the value of the W-E lease if it cannot be repaired or bought, the W-E reduction in value or spare parts. In the event that a leased W-E is damaged the above mentioned costs shall be supplemented, as the case may be, by the penalties stipulated by the contractual clauses or as a result of a court action. The calculation of the loss caused by the failure to perform maintenance is difficult and cannot be applied uniformly because of the large variations from one case to another; therefore a detailed analysis must be carried out to identify all aspects. For example, you need to know if the damaged W-E is the property of the company or it is leased, leased and what is the lifetime guaranteed by the manufacturer, the year of commissioning, the W-E efficiency, if the repair is done wholly or partly by the user or by contracting, etc.

If the lack of maintenance also results in work accidents or occupational disease, or during maintenance operations, the cost of corrective maintenance shall be supplemented by the cost of such occupational accidents or occupational disease.In fig. no. 3 are presented the lack of maintenance and of non-safety main parameters

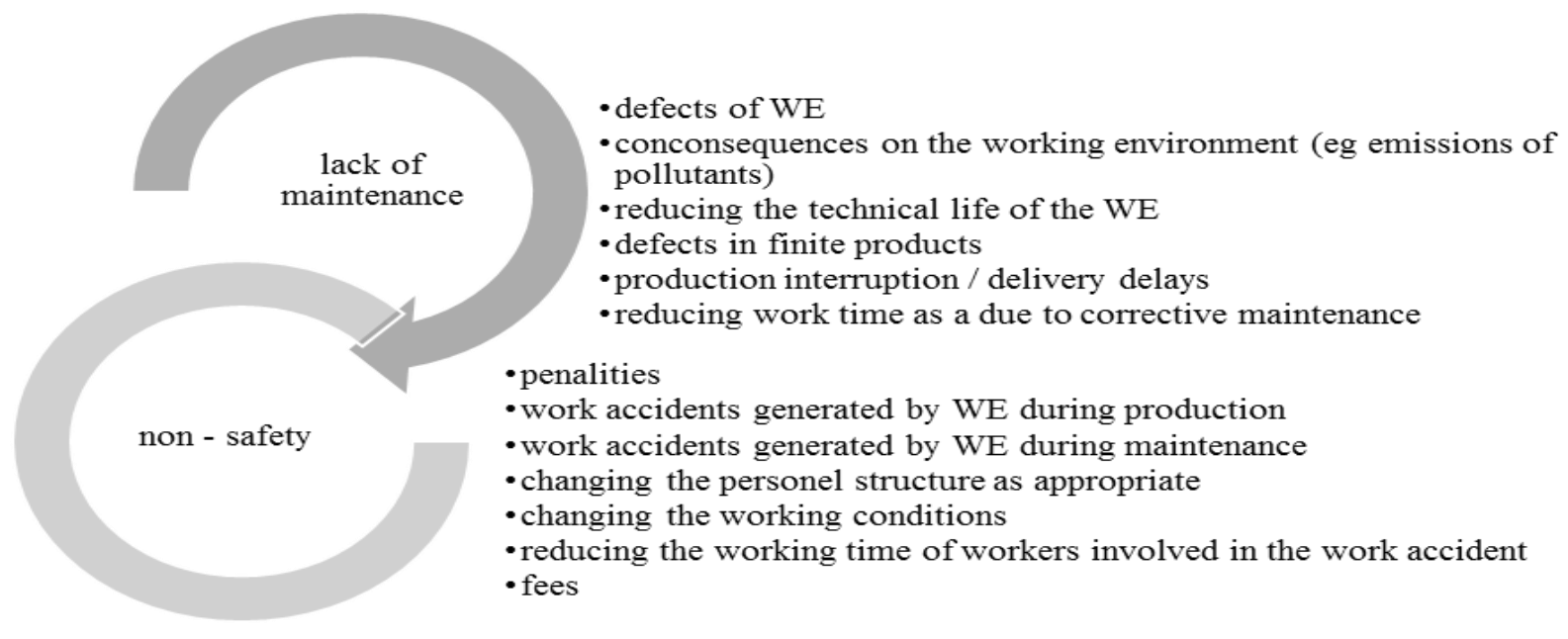

Fig.3. Lack of maintenance and of non-safety main parameters 


\section{Case Study}

The case study aims to analyze an event which led to failure of the on / off command system of a conveyor belt, due to the dust accumulated in the housing. To reduce loss of production during maintenance, as a result of replacement of the control system, the conveyor belt was powered directly from the electrical panel. The operation of supplying the conveyor belt directly from the electric panel - a non-compliant operation, because this solution eliminated the belt safety systems, against electric shock, lasted three hours. Therefore, the company recorded a loss of production time for the production line of the defective conveyor. After eight hours of operation, as a result of the speed increase, in order to recover the lost production time, one of the drive motors was also damaged, the conveyor belt being shut down to replace the engine for 120 hours. In this situation, $\mathrm{C}_{\mathrm{t}}$ costs are generated by the defective work equipment to be replaced CWE_1 (cost for control system) and CWE_2 (cost for electric drive motor), the value of lost and unrecovered production overtime, the cost of overtime Cover time, the cost of consumables and materials used during maintenance Consumable, plus the cost of safety tests Csafety, after repairs or replacements and, where appropriate, the cost of the protection (Dascalescu, 2003) ${ }^{[10]}$.

$$
\mathbf{C}_{\mathbf{t}}=\mathbf{C}_{\mathbf{w E}_{-} 1}+\mathbf{C}_{\mathbf{w E}_{-}{ }_{2}}+\mathbf{C}_{\text {consumable }}+\mathbf{C}_{\text {overtime }}+\mathbf{C}_{\text {safety }}
$$

\subsection{Costs due to failure of work equipment}

The costs resulting from the failure of the two work equipment are given by the value of the equipment at the time of the fault, the number of years left until removing from use, the average hourly efficiency and the actual use time per year.

$$
\mathbf{C}_{\mathbf{E M}_{-} l}=\mathbf{V}_{\mathbf{r}}+\overline{\mathbf{R}}_{\mathbf{h o}} \times \mathbf{T}_{\text {ind }}+\left(\mathbf{a}_{\mathbf{i a}}+\mathbf{a}_{\mathbf{l o}}\right) \times 12 \times \mathbf{n}_{\mathbf{a}} \times \phi
$$

The meaning and the values of all terms from eq. (2) are given in table 1 .

Costs of failure for $\mathrm{WE}_{1}$ : $\mathbf{C}_{\mathbf{W E}_{-1}}=3460,5$ lei

Costs of failure for $\mathrm{WE}_{2}$, is calculated similar to eq.(2)

$\mathbf{C}_{\mathrm{WE}_{-2}}=7686,5$ lei

\subsection{Costs of supplies used in maintenance}

Quantification of the costs for consumables and supplies used in the maintenance operation can only be done if there is clear evidence of the quantity of materials used, a breakdown for each category of maintenance operations. Taking into account that the value of this materials and consumables does not influence the losses of a company, we consider that the losses from the use of consumables are given by the quantity of material $\mathrm{q}$ and the price per unit purchased, (Dascalescu, 2003) ${ }^{[10]}$.

$$
\mathbf{C}_{\text {consumable }}=\sum_{\mathbf{n}=1}^{\infty} \mathbf{q}_{\mathbf{n}} \times \mathbf{p}_{\text {consumable }}+\sum \mathbf{C}_{\mathbf{m}}=28 \text { lei (3) }
$$

The meaning and the values of all terms from (3) are given in table 1.

\subsection{Cost of overtime}

In the case of maintenance, the maintenance team carried out 3 additional hours plus the cost of the overtime worked by the production workers to cover the band's functions. In order not to record the penalties specified by the contractual provisions and to be excluded from future bids, the company made the decision to pay additional 4 workers. The costs generated by these actions are (Dascalescu, 2003) ${ }^{[10]}$

$$
\begin{gathered}
\mathbf{C}_{\text {overtime_maintenance }}=\sum \mathbf{N}_{\mathbf{m}} \times \sum \mathbf{t}_{\mathrm{m}_{-} \text {overtime }} \times \sum \overline{\mathbf{S}}_{\mathbf{m e m t}}=80.7 \text { lei } \\
\mathbf{C}_{\text {overtime_maintenance }}=\sum \mathbf{N}_{\mathbf{m}} \times \sum \mathbf{t}_{\mathbf{m}_{-} \text {overtime }} \times \sum \overline{\mathbf{S}}_{\mathbf{m e m} \mathbf{t}}=\mathbf{6 5 4 . 6 \text { lei }}
\end{gathered}
$$

In the calculation of non-maintenance costs, the time lost since the finding, the failure communication and the arrival of the maintenance team were taken into account, and this time is counting in the production time losses, respectively the value of the lost production.

\subsection{Safety cost}

The safety costs are limited to the purchase of a mean of protection worth 120 lei, and the safety tests specified by EO no.
$1146 / 2006^{[11]}$. In this regard, the company contracted firm for safety tests, costing 520 lei. These safety tests should have been made annually. The means of protection that is part of the electrical part of the work equipment and the PPE used (mechanical protection gloves, 2pcs $\times 2.23$ lei) according to the economic records are recorded in the consumables category. In this study they are included in safety costs category, as a result of their role.

Total costs of non-maintenance $C_{t}=12554.76$ lei 
Table 1: Data necessary for the maintenance calculation

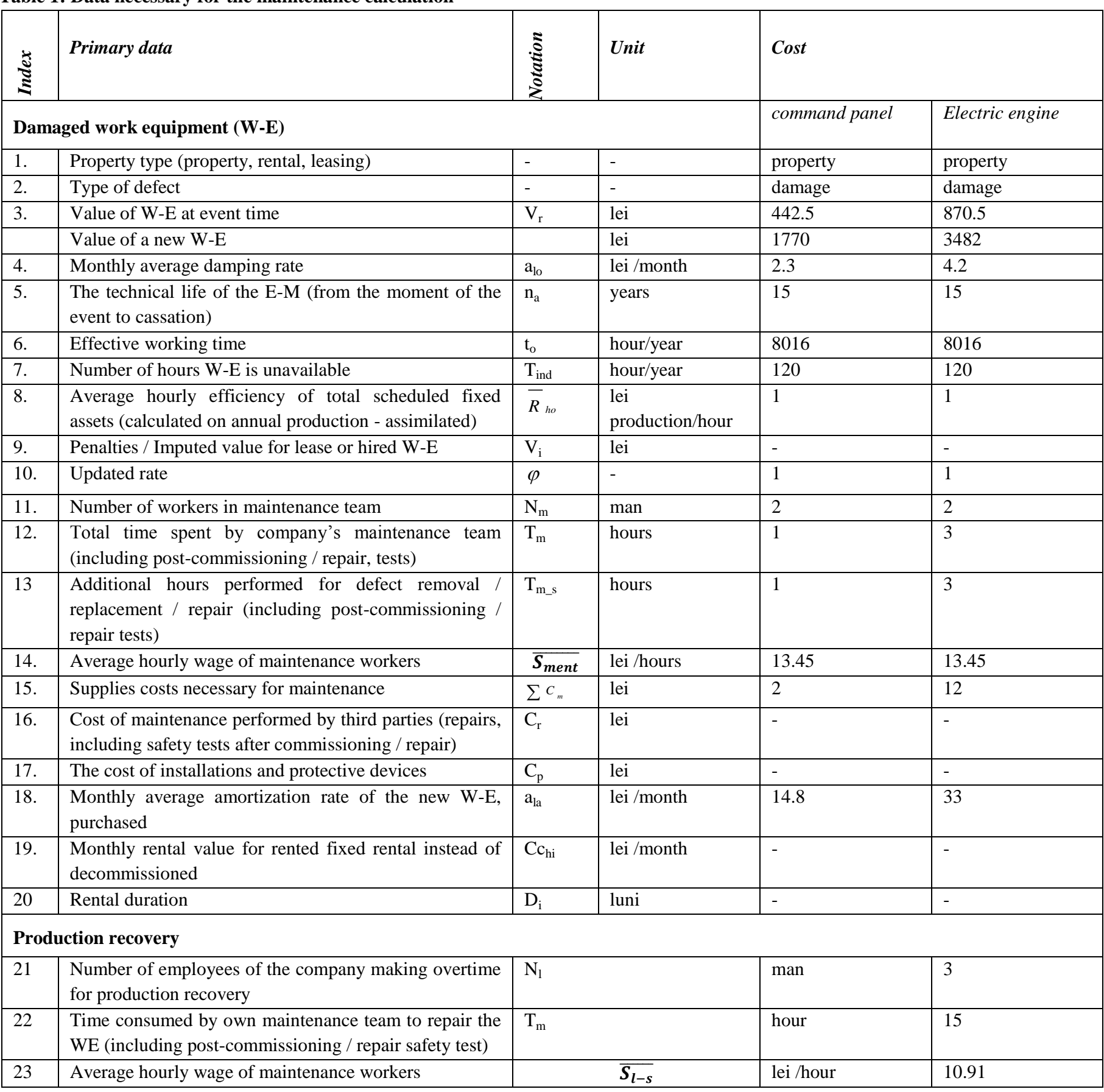

Lack of preventive maintenance by periodic technical and safety test, use of a non-compliant component of the electrical parts of the production line (the protection provided by the control system housing is non-compliant with the environment in which the housing is used) and the mental stress exerted on the maintenance workers and line operators, in order to recover the production to honor the contracts, led to a cost of 12554.76 lei. By analyzing economically the preventive measures that should be taken by the employer in this case study, it is found that non-maintenance costs could have been reduced to the cost of the maintenance team's time or to the maintenance electrician time for simple visual inspection and replacement of the housing or control system and, where appropriate, the cost of the safety test performed by the third party. Through a preventive maintenance to verify the technical condition of the control system and the protection against electric shock by direct touching the housing and cleaning up the housing until the replacement of the housing or the entire control system, maintenance costs would include the cost of maintenance hours the company's employees (hours $\mathrm{x}$ average hourly wage $=26.9$ lei) and the costs of the third party tests $(520$ lei).The total cost of maintenance $=546.9$ lei.

Maintenance activity management, as well as the occupational health and safety management system are the key component which has to be integrated in the company's general management system and its implementation should be made by integration in other management systems which are relevant for the organization, such as quality, environment or social responsibility. (D. Darabont et. al., 2017 ${ }^{[12]}$. For the efficiency of these results, this analysis has to be included in the internal audit, in this way the activity of internal auditors is organized as a permanent system, which has its own objectives and disposes of resources (human, material and financial) as well as adequate instruments (auditing method) (Vasilescu et al. 2012) ${ }^{[13]}$. 


\section{Conclusion}

Lack of maintenance changes negatively the result indicators of a company (turnover, value added, physical output, production costs), thus changing the profitability of the firm's business. Lack of maintenance leads to non - safety of workers, respectively production operators and maintenance workers. Although the investment in maintenance and implicitly in worker's safety is analyzed, mainly by managers, as any investment, in terms of cost and profit, it has to be addressed also in terms of the costs generated by an event, resulting in technical losses estimated in the basis of their production history, and sometimes work accidents and occupational disease.

\section{Acknowledgment}

The authors would like to acknowledge the keen support for this work of the Department of Physics, Faculty of Science, University of Tabuk, Saudi Arabia and the Faculty of Exact Sciences and Engineering, University "1 Decembrie 1918" Alba-Iulia, Romania and also niversity of Petrosani, 20 Universitatii str, Petrosani, România ${ }^{[14-19]}$.

\section{References}

[1] Antonov A, Buica G., Darabont D., Beiu C., (2015), The impact of occupational hazards in workplaces maintenance, a main target for ensuring the safety of work equipments, International Conference on Manufacturing Science and Education, Sibiu

[2] Buică G., (2010), Contributions of diagnostic methods of safty and health at work in electrical installations, Universitas, Petroşani, 70 - 79.

[3] Antonov A, Buica G., Beiu C., (2014), Management and control of occupational risk in the maintenance activities of work equipment in companies using software tools, Environmental Engineering and Management Journal, 13, 1361-1364

[4] Păsculescu D, Lupu L, Păsculescu V, Inişconi I, Şuvar M, (2012), Study of electrocution hazards in three-phase electrical networks with ground-isolated neutral point, Environmental Engineering and Management Journal, July 2012, Vol.11, No. 7, 1267-1271.

[5] Antonov A., Buica G., Beiu C. (2013), Maintenance software of work equipment, Magazine OBJECTIV No.2/2014, 26-29.

[6] Buica G., Beiu C., Antonov A, Iorga I (2012), Safety measures - tools for reducing the cost of working accidents in electrical installations, Environmental Engineering and Management Journal, July 2012, Vol.11, No. 7, 1247-1255.

[7] Radu SM, Pasculescu VM (2013) Safety level assessment in potentially explosive atmospheres - Recent Advances in Industrial and Manufacturing Technologies, 98-103.

[8] Antonov A., (2011), Machine maintenance - requirement for safety and health of workers, OSHA campaign
"Together for safe and healthy workplaces", ISBN 978606-921116-8-7.

[9] Buica G., (2011), Prevention of electrical risk and maintenance, OSHA campaign "Together for safe and healthy workplaces”, ISBN 978-606-921116-8-7.

[10] Dascalescu A., (2003), The cost of working accidents, (Book); Atlas Press, Bucharest, 162- 173.

[11] GD 1146/2006 concerning the minimum safety and health requirements for the use of work equipment by workersatwork,onlineat:https://osha.europa.eu/fop/roman ia/ro/legislation/hotarare_1146_30_august_2006.shtml.

[12] Darabont D, Antonov A, Bejinariu C, (2017) Key elements on implementing an occupational health and safety management system using ISO 45001 standard, International Conference on Manufacturing Science and Education - MSE 2017 "Trends in New Industrial Revolution", Sibiu

[13] Vasilescu GD, Găman A, Drăghici A, Simion S, An efficient integrated method for occupational health and safety internal auditing, applicable to complex working systems in hydroelectric power generation sector, Source: Environmental Engineering \& Management Journal (EEMJ) . July 2012, Vol. 11, No.7, 1273-1280.

[14] Adina Tatar, M. Ayaz Ahmad, Georgeta Buica, Dragos Pasculescu,(2016) "Development of Desulfurization Process in Romanian Thermal Power Plants", International Journal of Civil Engineering and Technology, 7(2), (2016), 193-202.

[15] Mircea Resteiu, Remus Dobra, Dragos Pasculescu, M. Ayaz Ahmad, "Quality Engineering Tools Focused on Designing Remote Temperature Measurements for Inaccessible Locations by Using Light Components Parameterization of the Heated Materials", IOP Conference Series Materials Science and Engineering, Vol. 133, (2016), pp. 012059. doi:10.1088/1757$899 X / 133 / 1 / 012059$

[16] Maria Loredana Boca, Remus Dobra, Dragos Pasculescu, M. Ayaz Ahmad, "Analysis and simulation of industrial distillation processes using a graphical system design model", Proc. SPIE, Vol. VIII (10010), (2016), pp. 100102U-1-8, doi:10.1117/12.2245971

[17] Nursabah Sarikavkli, M. Ayaz Ahmad, Remus Dobra, Dragos Pasculescu, "Nano-Technology for a Novel Photon Detector Systems" Vol. IV (2016), 51-54. Smart Applications \& Technologies for Electronic Engineering, SATEE 2016; ISBN: 978-606-613-128-5; www. satee.uab.ro; Romanian Chapter of IEEE Instrumentation and Measurements Society, University of Alba Iulia, 2016

[18] Remus Dobra, Dragos Pasculescu, M. Ayaz Ahmad, "Simulation of Electromagnetic Field Distribution Generated by Wave Transmitters", Asian Academic Research Journal of Multidisciplinary (AARJ), Vol. 3(1), (2016), pp. 160-173.

[19] Dragos Pasculescu, Remus Dobra, M. Ayaz Ahmad, "Dosimetric Quantity System for Electromagnetic Fields Bio-effects", International Journal of Scientific Research (IJSR),Vol. 5(2), (2016), pp. 28-32. 